\title{
Phylogenetic analysis and phenotypic characterisatics of two Tibet EV-C96 strains
}

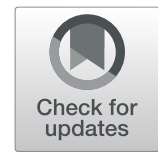

\author{
Lan $\mathrm{Hu}^{1,2}$, Yong Zhang ${ }^{1 *}$ (D) Mei Hong ${ }^{3}$, Qin Fan ${ }^{1,4}$, Dongmei Yan ${ }^{1}$, Shuangli Zhu', Dongyan Wang ${ }^{1}$ and \\ Wenbo $\mathrm{Xu}^{1,5^{*}}$
}

\begin{abstract}
Background: Enterovirus C96 (EV-C96) is a newly named type of enterovirus belonging to species C, and the prototype strain (BAN00-10488) was firstly isolated in 2000 from a stool specimen of a patient with acute flaccid paralysis in Bangladesh. In this study, we report the genomic and phenotypic characteristics of two EV-C96 strains isolated from individuals from the Tibet Autonomous Region of China.
\end{abstract}

Methods: Human rhabdomyosarcoma (RD), human laryngeal epidermoid carcinoma (HEp-2), and human cervical cancer (Hela) cells were infected with the Tibet EV-C96 strains, and enterovirus RNA in the cell culture was detected with a real time RT-PCR-based enterovirus screening method. The temperature sensitivity of Tibet EV-C96 strains were assayed on a monolayer of RD cells in 24-well plates. Full-length genome sequencing was performed by a 'primer-walking' strategy, and the evolutionary history of EV-C96 was studied by maximum likelihood analysis.

Results: Strain 2005-T49 grew in all three kinds of cells, and it was not temperature sensitive. In contrast, none of the three cells produced CPE for strain 2012-94H. Phylogenetic analysis of the two Tibetan viruses, other EV-C96 strains, and EV-C prototypes showed that EV-C96 strains were grouped into three clusters (Cluster1-3) based on their VP1 sequences, which may represent three genotypes. Phylogenetic trees based on the $P 2$ and $P 3$ regions highlighted the difference between Chinese EV-C96 strains and the EV-C96 prototype strain BAN-10488. All Chinese strains formed a cluster separate from BAN-10488, which clustered with CV-A1/CV-A22/CV-A19.

Conclusions: There is genetic variability between EV-C96 strains which suggest that at least few genetic lineages co-exist and there has been some degree of circulation in different geographical regions for some time. Some recombination events must have occurred during EV-C96 evolution as EV-C96 isolates cluster with different EV-C prototype strains in phylogenetic trees in different genomic regions. However, recombination does not seem to have occurred frequently as EV-C96 isolates from different years and locations appear to cluster together in all genomic regions analysed. These findings expand the understanding of the characterization of EV-C96 and are meaningful for the surveillance of the virus.

Keywords: Enterovirus C96, Cell sensitivity, Phylogenetic analysis, Recombinant

\section{Background}

Enteroviruses (EVs) are small, non-enveloped, singlestranded RNA viruses belonging to the family Picornaviridae, which can be classified to 12 species, including nine enteroviruses, Enterovirus A (EV-A) to $\mathrm{EV}-\mathrm{H}$, and EV-J and three rhinoviruses, Rhinovirus A-C [1].

\footnotetext{
*Correspondence: yongzhang75@sina.com; wenbo_xu1@aliyun.com 'WHO WPRO Regional Polio Reference Laboratory and NHC Key Laboratory of Biosafety, National Institute for Viral Disease Control and Prevention, Chinese Center for Disease Control and Prevention, Beijing, People's Republic of China

Full list of author information is available at the end of the article
}

Species EV-A-D correspond to the enteroviruses formerly named Human enterovirus A-D, and species EV-C currently consists of 23 serotypes: three polioviruses (PV) type 1-3, nine group A coxsackieviruses (CV-A1, A11, A13, A17, A19-22, and A24), and 11 new EV-C types, including EV-C95, EV-C96, EV-C99, EV-C102, EV-C104, EV-C105, EV-C109, EV-C113, and EV-C116-C118 [2-7]. EV-C has been correlated with a wide variety of clinical manifestations, ranging from mild respiratory infections to severe central nervous system infections, such as acute flaccid paralysis (AFP) and

(c) The Author(s). 2019 Open Access This article is distributed under the terms of the Creative Commons Attribution 4.0 International License (http://creativecommons.org/licenses/by/4.0/), which permits unrestricted use, distribution, and 
acute haemorrhagic conjunctivitis [8,9]. Generally, enterovirus genomes contain approximately 7500 nucleotides consisting of a single open reading frame that is flanked by $5^{\prime}$ and $3^{\prime}$ untranslated regions (5' - and $3^{\prime}$-UTRs). The single open reading frame is translated as a single polypeptide that is then autocatalytically cleaved to yield three polyprotein precursors: P1, P2, and P3. Polyprotein P1 is further cleaved to generate capsid proteins VP1-VP4, and P2 and P3 are cleaved to generate non-structural proteins named $2 \mathrm{~A}-2 \mathrm{C}$ and $3 \mathrm{~A}-3 \mathrm{D}$, respectively.

The molecular typing method used in recent years to identify different types of enteroviruses is equivalent to the formerly used neutralisation test $[10,11]$. The recommended criteria for the molecular typing method are based on the genetic diversity of VP1 region: EVs that share $>75 \%$ nucleotide identity and $>88 \%$ amino acid identity in the VP1 region are classified as the same type $[11,12]$.

EV-C96 is a recently described serotype in the EV-C species based on the molecular typing method [13] and the prototype strain (BAN00-10488) was first isolated in 2000 from a stool specimen of a patient with AFP in Bangladesh [5]. Subsequently, several other EV-C96 strains were isolated from patients with AFP or healthy individuals (asymptomatic infections) in Finland, Slovakia, the Philippines, Cambodia, China, and Bolivia [13-19]. Here, we report the complete genome sequences of two EV-C96 strains, 2005-T49/XZ/CHN/2005 (hereafter referred to as 2005-T49) and 2012-94H/XZ/CHN/2012 (hereafter referred to as 2012-94H), which were isolated in Tibet, China. Currently, 41 VP1 sequences, including 11 entire VP1 sequences and 9 complete genome sequences, of EV-C96 strains are available in GenBank, which we used to perform an evolutionary analysis of EV-C96. This study expands the number of EV-C96 full-length genome sequences in GenBank and provides valuable information regarding the molecular epidemiology of EV-C96.

\section{Methods \\ Sample collection}

Two stool samples were collected in the Tibet Autonomous Region in 2005 and 2012, respectively. One (2005-T49) was collected from a patient with AFP in 2005 in Lazi County in the Rikaze Prefecture of Tibet during the course of poliovirus surveillance in support of the global polio eradication initiative, and the other $(2012-94 \mathrm{H})$ was collected from a healthy child in Zhangmu County in Rikaze Prefecture of Tibet during an enterovirus surveillance program of healthy children in 2012.

\section{Viral isolation and primary identification}

The stool sample (about $2 \mathrm{~g}$ ) was dissolved in $10 \mathrm{ml}$ of complete phosphate-buffered saline with antibiotics, $1 \mathrm{~g}$ of glass beads and $1 \mathrm{ml}$ chloroform, then shaked vigorously for 20 min using a mechanical shaker. Spined for $20 \mathrm{~min}$ at $1500 \mathrm{~g}$ in a refrigerated centrifuge, and finally aspirated the supernatant for further use. $0.2 \mathrm{ml}$ stool supernatant was inoculated into human rhabdomyosarcoma (RD), human laryngeal epidermoid carcinoma (HEp-2) and human cervical cancer (Hela) cells (all in Hank's maintenance medium) and incubated at $36^{\circ} \mathrm{C}$ for virus propagation, then the cells were examined for the development of EV-like cytopathic effects (CPE) daily, recorded all observations of inoculated and control cultures for at least 7 days [20]. If characteristic enterovirus $\mathrm{CPE}$ appeard, then stored at $-20{ }^{\circ} \mathrm{C}$ for further use; If no CPE appeard after 7 days observing, performed a blind passage and continued examination for further 7 days. Enterovirus RNA was extracted from the cell culture using the QIAamp Viral RNA Mini Kit (Qiagen, Hilden, Germany), and was detected with a real time RT-PCR-based enterovirus screening method [21]. An EV-B85 strains, HYTY-ARL-AFP02F [22], was used as positive control, the $\mathrm{RD}$ cell culture without inoculating any samples was used as negtive control.

\section{Assay for temperature sensitivity}

For poliovirus vaccine strains, temperature sensitivity usually correlates with attenuation, and vaccine-derived mutant strains which have lost their temperature sensitivity have been shown to be neurovirulent, so temperature sensitivity may be an acceptable method for evaluating the presence of attenuating mutations for enteroviruses [23]. The temperature sensitivity of EV-C96 strain 2005-T49 was assayed on a monolayer of RD cells (CCL-136, ATCC, Passage number is 241) in 24-well plates [24]. We could not assess the temperature sensitivity of strain $2012-94 \mathrm{H}$ because it did not induce CPE in RD, HEp-2 or Hela cells. Add 100 ul of RD cells from a cell suspension containing $2 \times 10^{5}$ cells $/ \mathrm{ml}$ to all wells in the 24-well plate, then the plates were inoculated with $50 \mu \mathrm{L}$ undiluted virus stocks. Two different incubators were used: one incubator was adjusted to $36^{\circ}$ $\mathrm{C}$ as the optimal temperature for virus propagation, and another one was adjusted to $39.5^{\circ} \mathrm{C}$ as the supraoptimal temperature for virus propagation. After adsorption at $36^{\circ} \mathrm{C}$ or at $39.5^{\circ} \mathrm{C}$ for $1 \mathrm{~h}$, the unadsorbed virus inoculum was removed and $100 \mu \mathrm{L}$ of maintenance medium (2\% Foetal calf serum in Eagle's minimum essential medium) was added to each well. The plates were continually incubated at $36^{\circ} \mathrm{C}$ or at $39.5^{\circ} \mathrm{C}$ and harvested at 7 time points post-infection $(8 \mathrm{~h}, 16 \mathrm{~h}, 24 \mathrm{~h}, 48 \mathrm{~h}, 72 \mathrm{~h}, 96$ $\mathrm{h}$, and $120 \mathrm{~h}$ ) in succession. The $50 \%$ cell culture infectious dose $\left(\mathrm{CCID}_{50}\right)$ was calculated by the SpearmannKärber end-point dilution method on monolayer RD cells in 96-well plates at $36^{\circ} \mathrm{C}$. Two Xinjiang EV-B85 strains, HYTY-ARL-AFP02F, which is not temperature sensitive, 
and HT-LYKH202F, which is temperature sensitive, [22] were used as experimental controls to ensure that the cells and viral replication were not affected at high temperature under the experimental conditions. Virus isolates showing more than a two-log reduction in titre at the elevated temperature were considered to be temperature sensitive [25].

\section{Full-length genome sequencing}

HEp-2 cell cultures of 2005-T49 (CPE observed) and 2012-94H (real-time RT-PCR positive although no CPE observed) were frozen three times to release viruses. For molecular typing, viral RNA was extracted from 140ul HEp-2 cell culture using the QIAamp Viral RNA Mini Kit (Qiagen, Hilden, Germany) and stored at $-80^{\circ} \mathrm{C}$ until use. RT-PCR was performed to amplify the VP1coding region using the PrimeScript ${ }^{\text {tw }}$ One Step RT-PCR Kit Ver.2 (TaKaRa, Dalian, China) with primers E292 and E222 [26]. The RT-PCR products were purified using the QIAquick PCR Purification Kit (Qiagen, Hilden, Germany), and then used for nucleotide sequencing. The EV serotype was determined according to a previously described molecular typing method [12]. The primers used for amplification and sequencing were designed by a 'primer-walking' strategy (Table 1). Viral RNA extraction, RT-PCR amplification, and PCR product purification were performed as described above.
Sequencing was performed in both directions using an ABIPRISM 3130 Genetic Analyzer (Applied Biosystems), and every nucleotide position was sequenced at least twice in order to ensure the accuracy of sequences.

The $5^{\prime}$ end sequence of the genome was obtained using a $5^{\prime}$ rapid amplification of cDNA ends (RACE) kit (Takara Biomedicals) according to the manufacturer's instructions. The 3 ' end sequence of the genome was obtained by amplification using an oligo-dT primer (primer 7500A) as the downstream primer listed in Table 1 . The $5^{\prime}$ end sequence of the genome was obtained from both the viral isolates and the stool samples.

\section{Phylogenetic and bioinformatics analyses}

The nucleotide and deduced amino acid sequences of strains 2005-T49 and 2012-94H were compared to those of the prototype EV-C strains by pairwise alignment using MEGA (version 7.0.26, [27]). The evolutionary history of EV-C96 was studied by maximum likelihood analysis. The maximum likelihood phylogenetic tree was constructed by the MEGA software and inferred by Model Finder to search the best nucleotide substitution model [28]. Regions containing alignment gaps were omitted from the analysis. The branch lengths of the dendrogram were determined from the topologies of the trees and were obtained by majority rule consensus among 1000 bootstrap replicates. Bootstrap values $>80 \%$

Table 1 PCR and sequencing primers

\begin{tabular}{|c|c|c|c|c|}
\hline Primer & Position & Primer sequence $\left(5^{\prime}-3^{\prime}\right)$ & Direction & Reference \\
\hline 0001548 & & GGGGACAAGTTTGTACAAAAAAGCAGGCTTAAAAACAGCTCTGGGGTT & Forward & [43] \\
\hline EV-C96-1075A & $1056-1075$ & GCCACTCTCCATAGGCAACT & Reverse & This study \\
\hline EV-C96-618S & $618-638$ & TCATAAAGCGAATTGGATTGG & Forward & This study \\
\hline EV-C96-1575A & $1555-1575$ & GGCACTATTGTTGGTTCTCAG & Reverse & This study \\
\hline EV-C96-1186S & $1186-1206$ & AAAGGTTGGTGGTGGAAATTA & Forward & This study \\
\hline EV-C96-2318A & $2298-2318$ & ACACATCTGCGGTACACACT & Reverse & This study \\
\hline EV-C96-2137S & $2137-2156$ & TGTGGTAGTATGATGGCCAC & Forward & This study \\
\hline EV-C96-3331A & $3312-3331$ & CTTGGACACCACACCCTGAT & Reverse & This study \\
\hline EV-C96-3087S & $3087-3107$ & CCACCGAGAATGTCTGTACCA & Forward & This study \\
\hline EV-C96-4396A & $4374-4396$ & TGAAGAGCACCTCTTGTTGTTC & Reverse & This study \\
\hline EV-C96-4148S & $4148-4168$ & TTACGTCATGAGACAGGGTGA & Forward & This study \\
\hline EV-C96-5337A & $5318-5337$ & AAATTGTCATCGCCCTGTTC & Reverse & This study \\
\hline EV-C96-5121S & $5121-5140$ & ATAGGCAATTGCATGGAAGC & Forward & This study \\
\hline EV-C96-6155A & $6136-6155$ & GAGGACTGCTGGTTCCTTGA & Reverse & This study \\
\hline EV-C96-5870S & $5870-5890$ & ACTGCTCGCACGCTAATGTA & Forward & This study \\
\hline EV-C96-6746A & $6722-6746$ & TGCATCATACCCTGTGTAATCA & Reverse & This study \\
\hline EV-C96-6551S & $6551-6570$ & GATCGAGGCATCAAGTCTCA & Forward & This study \\
\hline EV-C96-7435A & $7416-7435$ & CCAATTCGACTGAGGTAGGG & Reverse & This study \\
\hline EV-C96-7030S & 7030-7049 & CCCATGAGGTTGACGCTAGT & Forward & This study \\
\hline $7500 \mathrm{~A}$ & & GGGGACCACTTTGTACAAGAAAGCTGGG(T) 24 & Reverse & [43] \\
\hline
\end{tabular}


were considered statistically significant for grouping. Similarity plots and boot scanning analyses were performed using SimPlot (version 3.5.1; Stuart Ray, Johns Hopkins University, Baltimore, MD, USA) [29]. For the similarity plot analyses, a 200-nucleotide window was moved in 20-nucleotide steps, and boot scanning analyses were performed by using the neighbour-joining method.

\section{Data availability and nucleotide sequence accession} numbers

The full-length genome sequences of the two Tibetan EV-C96 strains described in this study, 2005-T49/XZ/ CHN/2005 and 2012-94H/XZ/CHN/2012, were deposited in the GenBank under the respective accession numbers KP984753 and KP984754.

\section{Results}

The two Tibetan EV-C96 strains showed different growth ability in cells

Tibetan EV-C96 strain 2005-T49 grew and showed clear CPE in RD cells, HEp-2 cells and Hela cells. In contrast, strain 2012-94H showed no CPE in these three cells. The results were similar when cultured at $33^{\circ} \mathrm{C}$ and $36^{\circ} \mathrm{C}$. However, viral RNA of $2012-94 \mathrm{H}$ in HEp-2 and Hela cell culture were detected by real-time RT-PCR assay with the cycle threshold (Ct) values of 25.85 and 28.15, respectively, and RD cell culture was real-time RT-PCR negative, suggesting low replication compared with 2005-T49 (Ct values of 17.25, 20.05, and 22.20, respectively, in HEp-2, Hela, and RD cell culture) and indicating a different growth ability in cells for strain 2012-94H (Fig. 1a).

The Tibet EV-C96 strains were not temperature sensitive The replication capacity of Tibetan EV-C96 strain 2005-T49 at an elevated temperature $\left(39.5^{\circ} \mathrm{C}\right)$ was compared with that of two Xinjiang EV-B85 strains, HYTYARL-AFP02F, which is not temperature sensitive, and HT-LYKH202F, which is temperature sensitive [22]. The results showed that Tibetan EV-C96 strain 2005-T49 was not temperature sensitive, based on the results that

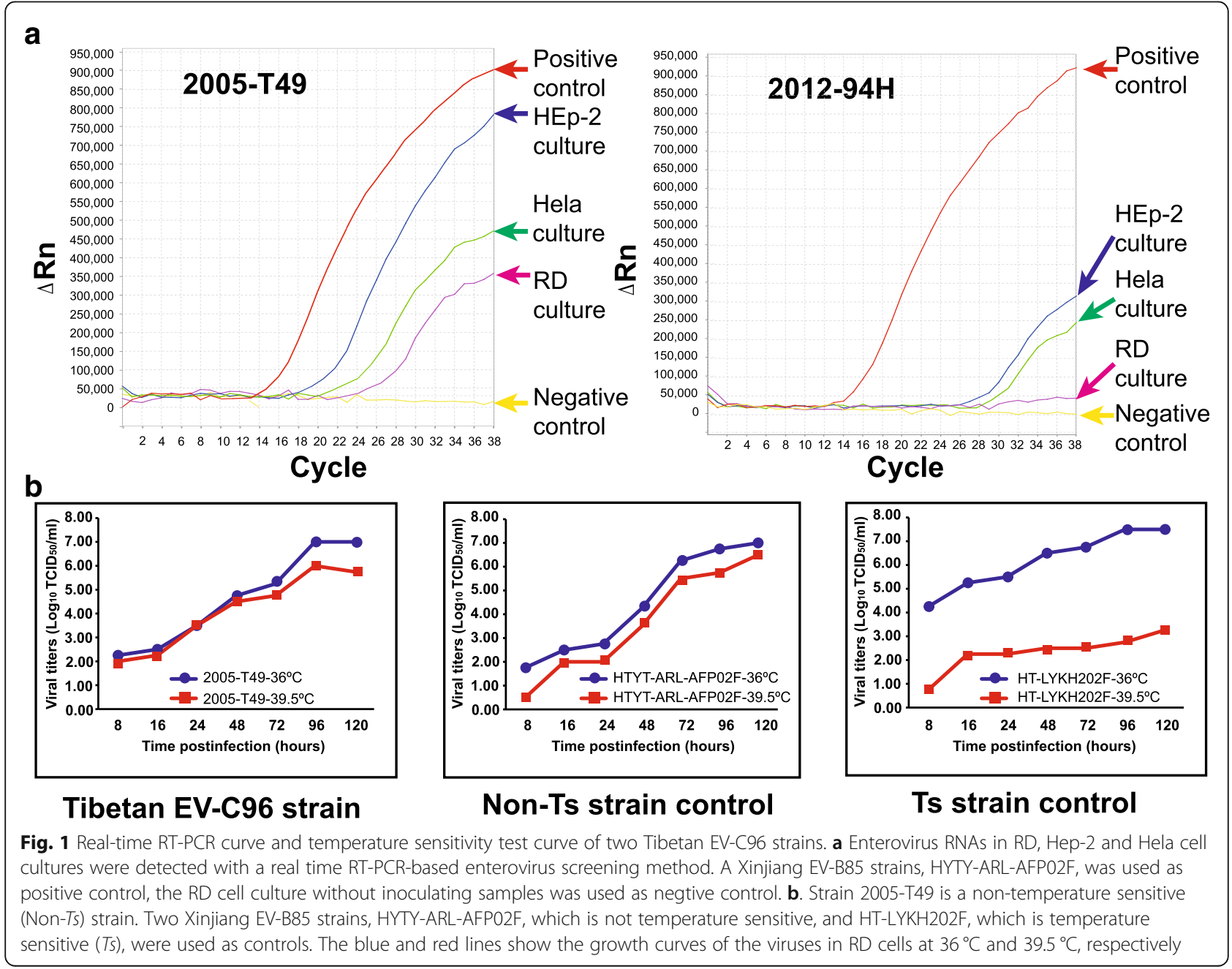


a titre reduction of less than 2 logarithms at $36^{\circ} \mathrm{C} /$ $39.5^{\circ} \mathrm{C}$ (Fig. 1b).

\section{Characterisation of the full-length genome sequence of the Tibetan EV-C96 strains}

The full-length genome sequences of two Tibetan EV-C96 strains, 2005-T49 and 2012-94H, were obtained. The lengths of the 2005-T49 and 2012-94H genomes were 7471 and 7453 nucleotides, respectively, and both encoded a 2219-amino acid polypeptide. The coding sequences were flanked by non-coding $5^{\prime}$-UTRs of 744 and 726 nucleotides, respectively, and non-coding 3'-UTR of 70 nucleotides each followed by a poly (A) tail composed of a long sequence of adenine nucleotides. The $5^{\prime}$ end sequences obtained from the stool specimens are identical to those obtained from the viral isolates. Alignment of the two Tibetan EV-C96 full-length genomes with the genome of the EV-C96 prototype strain BAN00-10488 showed that they shared the same genomic organisation and same order of genomic regions. However, in the 5'-UTR, one of the Tibet EV-C96 strains, 2005-T94, contained two nucleotide deletions at positions 120 and 139, and strain 2012-94H contained an 18-nucleotide deletion at positions 713-730, which is located in complex RNA elements termed internal ribosome entry sites (IRESs) [30, 31]. In the $3 A$ region, both strains contained a 3 -nucleotide deletion at position 5290-5292, and a 2-nucleotide deletion at 7407-7408 in the $3^{\prime}$-UTR. The overall base composition of strain 2005-T49 was $29.82 \%$ A, $22.94 \%$ G, $22.59 \%$ C, and $24.64 \% \mathrm{U}$, and that of $2012-94 \mathrm{H}$ was $29.99 \% \mathrm{~A}, 22.81 \%$ G, $22.55 \% \mathrm{C}$, and $24.65 \% \mathrm{U}$. The polypeptide cleavage sites were predicted based on the sequence of the EV-C96 prototype strain. The nucleotide and amino acid sequence identities in the VP1-coding region between strain 2005-T49 and 2012-94H were 87.3 and $94.4 \%$, respectively, and 2005-T49 and $2012-94 \mathrm{H}$ respectively displayed 79.1 and $78.5 \%$ nucleotide identity and 93.5 and $92.5 \%$ amino acid identity in the VP1 region with the prototype EV-C96 strain.

\section{Phylogenetic analysis of the Tibetan EV-C96 strains and other EV-C genomes}

To investigate the phylogenetic relationships among the two Tibetan EV-C96 strains and other EV-C96 strains, a phylogenetic tree was generated based on the VP1 region of the two Tibetan EV-C96 strains, all EV-C96 strains in GenBank, and all EV-C prototype strains (Fig. 2). In this tree, all EV-C96 strains were grouped with the prototype strain, and could be grouped into three clusters, as described previously [32]. One cluster (Cluster 1), contained strains from China, including all Chinese EV-C96 strains, Cambodia, and Finland; the second (Cluster 2), contained strains from Slovenia and
Bangladesh as well as the prototype strain; and the third (Cluster 3) contained strains from Finland.

Phylogenetic trees based on the $P 1, P 2$, and $P 3$ regions were also generated (Fig. 3). In the $P 1$ region-based tree, all EV-C96 strains were clustered together with the EV-C96 prototype strain. The serotype with the highest sequence similarity to the EV-C96 strains is CV-A24. No sub-cluster was observed because full-length genome sequences were not available for all EV-C96 strains. In the $P 2$ and $P 3$ region-based trees, the EV-C96 prototype strain, BAN-10488, and strain FIN04-7 formed a monophyletic cluster that did not group with any other EV-C96 strains or other EV-C types, and all Chinese EV-C96 strains were still clustered with CV-A24 and $\mathrm{CV}-\mathrm{A} 24 \mathrm{v}$ (Fig. 3). In all the trees mentioned above, the two Tibetan EV-C96 strains were close to each other, and were together with all other Chinese strains.

\section{Recombinant analysis of the EV-C96 strains}

The phylogenetic analyses based on the $P 2$ and $P 3$ regions showed that the prototype EV-C96 strain BAN-10488 and the Chinese EV-C96 strains were on separate branches in a cluster formed by the EV-C prototypes. Strain BAN-10488 and the Chinese EV-C96 strains diverged by $28.65 \%$ in the $P 2$ and $P 3$ regions, and they diverged by $19.15-29.33 \%$ and $19.25-31.69 \%$, respectively, from other EV-C prototype strains. Some recombination events must have occurred during EV-C96 evolution as EV-C96 isolates cluster with different EV-C prototype strains in phylogenetic trees in different genomic regions. However, recombination does not seem to have occurred frequently as EV-C96 isolates from different years and locations appear to cluster together in all genomic regions analysed.

A similarity analysis was also performed to investigate potential recombination in EV-C96 strains, and strain 2005-T49 were used as query sequences for comparison to the EV-C prototype strains. The similarity analysis demonstrated that the two Tibetan EV-C96 strains showed the highest sequence similarity with the EV-C96 prototype only in the $P 1$ region. However, in the $P 2$ and P3 regions, the similarity between BAN-10488 and the Chinese EV-C96 strains was of the same magnitude as that between heterotypic EV-C prototype strains.

\section{Discussion}

EV-C species viruses have been shown to be correlated with many diseases, such as poliomyelitis caused by poliovirus [33] and acute haemorrhagic conjunctivitis caused by CV-A24v [34]. In a previous study, EV-C-type viruses were clustered into three subgroups based on the VP1-coding region [35], and EV-C96 is clustered with CV-A21, CV-A24, EV-C95, and EV-C99. Notably, more than twenty cases of EV-C96 infection were reported in 


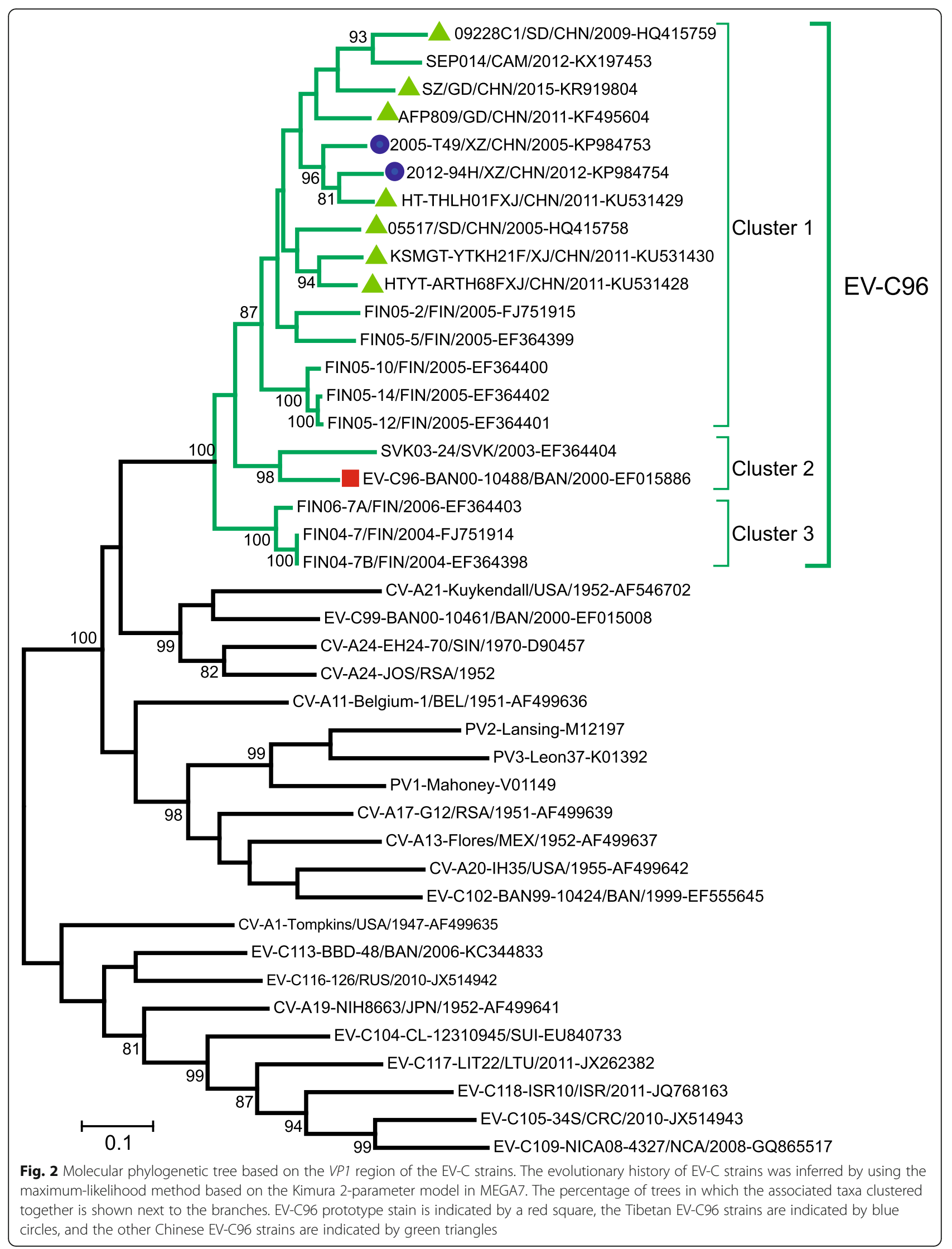




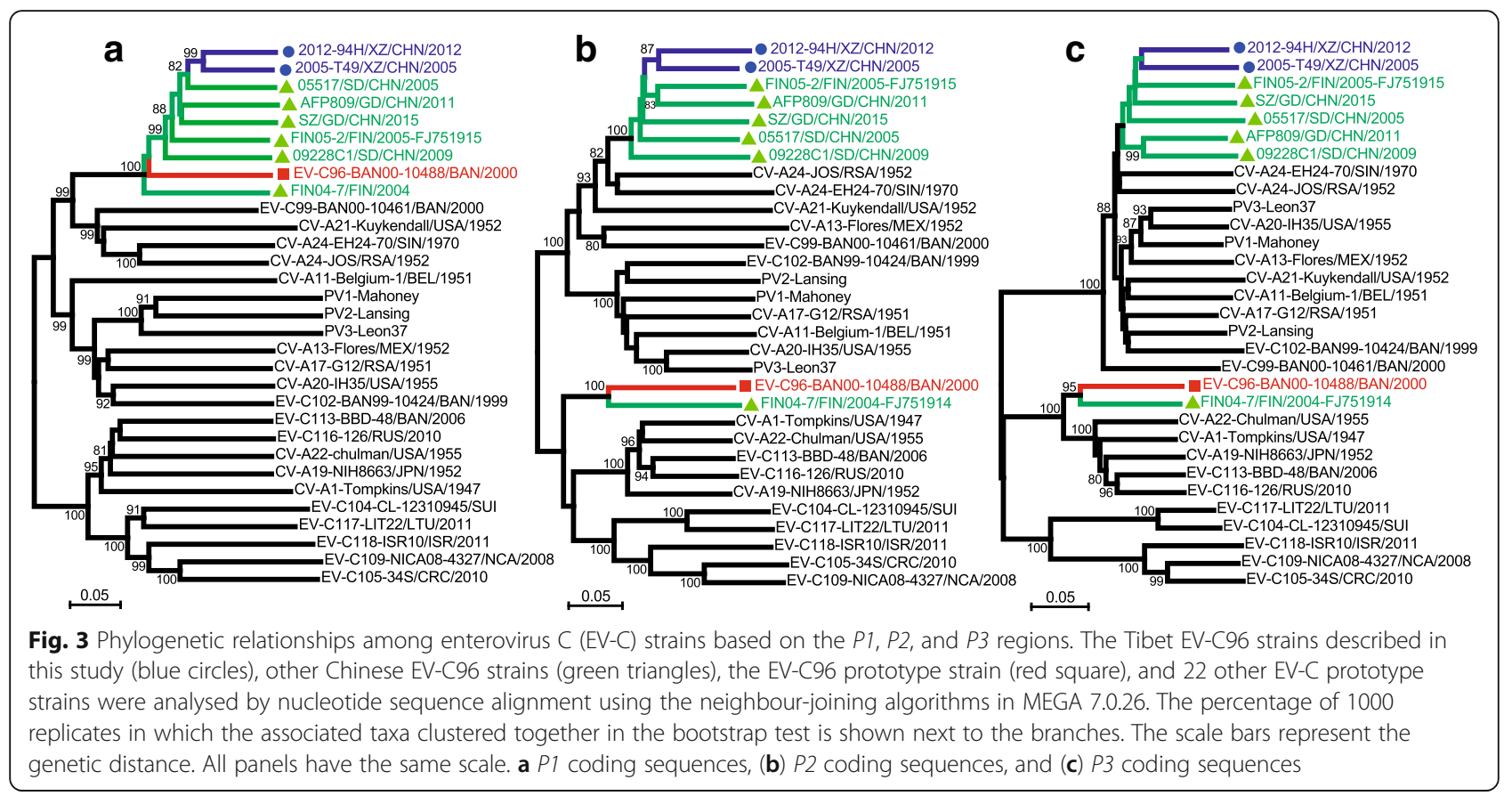

several provinces of China, including Shandong [17], Guangdong [32], Xinjiang [3], and Yunnan province [36], and most of these strains were isolated from patients with AFP, like in other countries, which suggests that EV-C96 may be an important etiological cause of AFP.

It was previously shown that different EV-C96 strains have different cell tropisms in RD and HEp-2 cells [32]. In this study, the two EV-C96 strains also showed different growth abilities in cells that differed from those of previously described EV-C96 strains. Although strain 2012-94H showed no CPE in RD, HEp-2 or Hela cells, however, viral RNA can be detected in HEp-2 and Hela cell cultures by real-time RT-PCR assay. Clearly, the virus could still replicate in the HEp-2 and Hela cells, it just did not produce CPE. So indeed, viral culture in immortalised cell lines does not necessarily have relevance to tissue tropism in vivo. The growth ability in cells could be affected by many things, changes in cell lines during repeated passages may have influenced the ability of $2012-94 \mathrm{H}$ to replicate in these cell lines. Therefore, further studies are needed to clarify the different growth abilities in different cells among different EV-C96 strains.

Interestingly, the full-length genome sequencing showed that strain 2012-94H has a deletion of 18 nucleotides in the IRES element in $5^{\prime}$-UTR. It is known that two major types of IRES element have been identified within picornaviruses, enteroviruses (include polioviruses and rhinoviruses) contain type I IRES, whereas the cardioviruses and foot-and-mouth disease viruses share another type of IRES, type II IRES. Although sequence identity between different members within type I IRES can be less than $50 \%$, the secondary structure predictions are very similar [30, 37]. It has been shown that the $5^{\prime}$-UTR of enteroviruses plays an important role in RNA replication and the translation of viral proteins because of its cloverleaf-like secondary structure and IRES [38, 39]. Although there is not enough evidence yet, we hypothesise that this 18-nucleotide deletion in the 5'-UTR may affect viral replication, and may be one of the reasons why strain 2012-94H does not cause CPE in RD, HEp-2 and Hela cells. Our research team is currently using reverse genetic methods to elucidate the inherent mechanism of this interesting finding.

The full-length genome characterisation showed that the two Tibetan EV-C96 strains share high nucleotide sequence similarity with the EV-C96 prototype strain BAN00-10488 only in the $P 1$ region, which encodes the capsid protein of the virion. In contrast, in the nonstructural coding regions $P 2$ and $P 3$, the Tibetan strains showed higher genetic diversity when compared with EV-C prototype strains, including BAN00-10488, which is in agreement with the phylogenetic trees described above. EV-C96 strains from two different countries, China and Finland, showed a close phylogenetic relationship with each other, although there is no clear epidemiological evidence, this could be explained by the fact that the strains from Finland that belong to cluster 1 were thought to be imported from China [13]. The genetic diversity in the VP1 region among the Chinese strains isolated in 2005-2012 indicated that EV-C96 has 
been circulating in China for many years and has been evolving.

Genetic recombination, an evolutionary pattern observed in most viruses, is a common phenomenon during the evolution of enterovirus [40, 41]. The junction between the $P 1$ region and the $P 2$ and $P 3$ regions may be a hotspot for recombination events, as exchanges here would not change the viral serotype or affect important functions [42]. The $P 2$ and $P 3$ regions of the Chinese EV-C96 strains were highly divergent from those of BAN-10488; in fact, the Chinese EV-C96 strains were divergent from all EV-C prototypes, and strain BAN-10488 was most similar to CV-A1/CV-A22/ CV-A19. The difference between the Chinese EV-C96 strains and BAN-10488 was also evident in the phylogenetic trees based on the $P 2$ and $P 3$ regions, in which all Chinese EV-C96 strains formed a separate cluster, and the BAN-10488 clustered with CV-A1/CV-A22/ CV-A19.

In this study, the full-length genomes of two EV-C96 strains isolated from the Tibet Autonomous Region of China were characterised, and their phylogenetic relationships with other EV-C96 strains and other EV-C serotypes were analysed. The different growth patterns on RD, HEp-2 and Hela cells among EV-C96 strains suggest a unique pattern of phenotypic characterisatics among viruses of this type, one of the reasons leading to this phenotypic character may be due to a deletion of 18 nucleotides in the IRES element in $5^{\prime}$-UTR, which is worthy of further study. There is genetic variability between EV-C96 strains which suggest that at least few genetic lineages co-exist and there has been some degree of circulation in different geographical regions for some time. The three clusters of EV-C96 in the P1-based tree may represent three different genotypes, and all Chinese EV-C96 strains belong to cluster 1 . These findings expand the understanding of the characterization of EV-C96 and are meaningful for the surveillance of the virus.

\section{Abbreviations \\ AFP: Acute flaccid paralysis; CCID $_{50}$ : 50\% cell culture infectious dose; CPE: Cytopathic effects; Ct: Cycle threshold; EV: Enterovirus; EV- C96: Enterovirus C96; Hela cell: Human cervical cancer cell; HEp-2 cell: Human laryngeal epidermoid carcinoma cell; IRES: Internal ribosome entry site; RD cell: Human rhabdomyosarcoma cell; UTR: Untranslated regions}

\section{Acknowledgments}

We would like to acknowledge the staff of the National Polio Eradication Program in the Tibet Autonomous Region Center for Disease Control and Prevention for collecting stool specimens from patients with acute flaccid paralysis for use in this study.

\section{Funding}

This study was supported by the National Key Technology R\&D Program of China (Project Nos. 2017ZX10104001, 2018ZX10711001, and 2018ZX10713002), National Natural Science Foundation of China (Project No. 81672070). The funding sources played no role in the study design and collection, analysis, and interpretation of data and in writing the manuscript.

\section{Availability of data and materials}

The datasets used or analysed during the current study are included in this published article and are available from the corresponding author on reasonable request.

\section{Authors' contributions}

YZ and $W X$ conceived and designed the experiments. LH, YZ, MH, QF, DY, $S Z$, and DW performed the experiments. $L H$ and $Y Z$ analysed the data. $L H$ and $Y Z$ wrote the manuscript and prepared the figures. All authors reviewed the manuscript. All authors read and approved the final manuscript.

\section{Ethics approval and consent to participate}

In this study, the only human materials used were stool samples collected from one patient with AFP and one healthy child under the direction of the National Health Commission of the People's Republic of China for public health purposes. This study was approved by the Ethics Review Committee of the National Institute for Viral Disease Control and Prevention, Chinese Center for Disease Control and Prevention. All experimental protocols were approved by National Institute for Viral Disease Control and Prevention, and the methods were carried out in accordance with the approved guidelines.

\section{Consent for publication}

In this study, the only human materials used were stool samples collected from one healthy child and one patient with AFP. Written informed consent for the use of their clinical samples was obtained from their parent involved in this study.

\section{Competing interests}

The authors declare that they have no competing interests.

\section{Publisher's Note}

Springer Nature remains neutral with regard to jurisdictional claims in published maps and institutional affiliations.

\section{Author details}

'WHO WPRO Regional Polio Reference Laboratory and NHC Key Laboratory of Biosafety, National Institute for Viral Disease Control and Prevention, Chinese Center for Disease Control and Prevention, Beijing, People's Republic of China. ${ }^{2}$ Department of the Laboratory, Guanghua Hospital of Traditional and Western Medicine, Changning District, Shanghai, People's Republic of China. ${ }^{3}$ Tibet Center for Disease Control and Prevention, Lhasa City, Tibet Autonomous Region, People's Republic of China. ${ }^{4}$ Zhejiang Center for Disease Control and Prevention, Hangzhou city, Zhejiang Province, People's Republic of China. ${ }^{5}$ Anhui University of Science and Technology, Hefei city, Anhui Province, People's Republic of China.

Received: 5 July 2018 Accepted: 22 March 2019

Published online: 29 March 2019

\section{References}

1. Knowles NJ, Hovi T, Hyypiä T, King AMQ, Lindberg M, Pallansch MA, Palmenberg AC, Simmonds P, Skern T, Stanway G, Yamashita T, Zell R. Picornaviridae. In: King AMQ, Adams MJ, Carstens EB, Lefkowitz EJ, editors. Virus taxonomy: classification and nomenclature of viruses: Ninth Report of the International Committee on Taxonomy of Viruses. Diego: Elsevier; 2011. p. 855-880.

2. Sun Q, Zhang Y, Cui H, Zhu S, Li X, Huang G, Tang H, Yan D, Wang D, Xu W. Complete genome sequence analysis of two human enterovirus C99 strains isolated in Xinjiang Uighur autonomous region, China, in 2011. Arch Virol. 2014;159:359-64.

3. Zhang Y, Sun Q, Cui H, Yan D, Fan Q, Song Y, Zhu S, Li X, Huang G, Ji T, et al. Circulation of multiple serotypes of highly divergent enterovirus $C$ in the Xinjiang Uighur autonomous region of China. Sci Rep. 2016;6:33595.

4. Smura T, Blomqvist S, Vuorinen T, Ivanova O, Samoilovich E, Al-Hello H, Savolainen-Kopra C, Hovi T, Roivainen M. Recombination in the evolution of enterovirus C species sub-group that contains types CVA-21, CVA-24, EVC95, EV-C96 and EV-C99. PLoS One. 2014;9:e94579.

5. Brown BA, Maher K, Flemister MR, Naraghi-Arani P, Uddin M, Oberste MS, Pallansch MA. Resolving ambiguities in genetic typing of human enterovirus species C clinical isolates and identification of enterovirus 96,99 and 102. J Gen Virol. 2009;90:1713-23. 
6. Tokarz R, Haq S, Sameroff S, Howie SR, Lipkin WI. Genomic analysis of coxsackieviruses A1, A19, A22, enteroviruses 113 and 104: viruses representing two clades with distinct tropism within enterovirus C. J Gen Virol. 2013;94:1995-2004.

7. Lukashev AN, Drexler JF, Kotova VO, Amjaga EN, Reznik VI, Gmyl AP, Grard G, Taty Taty R, Trotsenko OE, Leroy EM, Drosten C. Novel serotypes 105 and 116 are members of distinct subgroups of human enterovirus C. J Gen Virol. 2012:93:2357-62.

8. Luo HM, Zhang Y, Wang XQ, Yu WZ, Wen N, Yan DM, Wang HQ, Wushouer $F$, Wang $H B$, Xu AQ, et al. Identification and control of a poliomyelitis outbreak in Xinjiang, China. N Engl J Med. 2013;369:1981-90.

9. Yan D, Zhu S, Zhang Y, Zhang J, Zhou Y, Xu W. Outbreak of acute hemorrhagic conjunctivitis in Yunnan, People's Republic of China, 2007. Virol J. 2010;7:138.

10. Oberste MS, Maher K, Flemister MR, Marchetti G, Kilpatrick DR, Pallansch MA. Comparison of classic and molecular approaches for the identification of untypeable enteroviruses. J Clin Microbiol. 2000:38:1170-4.

11. Oberste MS, Maher K, Kilpatrick DR, Pallansch MA. Molecular evolution of the human enteroviruses: correlation of serotype with VP1 sequence and application to picornavirus classification. J Virol. 1999;73:1941-8.

12. Oberste MS, Maher K, Kilpatrick DR, Flemister MR, Brown BA, Pallansch MA. Typing of human enteroviruses by partial sequencing of VP1. J Clin Microbiol. 1999;37:1288-93.

13. Smura T, Blomqvist $S$, Paananen A, Vuorinen T, Sobotova Z, Bubovica V, Ivanova O, Hovi T, Roivainen M. Enterovirus surveillance reveals proposed new serotypes and provides new insight into enterovirus 5 -untranslated region evolution. J Gen Virol. 2007;88:2520-6.

14. Arita M, Zhu SL, Yoshida H, Yoneyama T, Miyamura T, Shimizu H. A Sabin 3derived poliovirus recombinant contained a sequence homologous with indigenous human enterovirus species $C$ in the viral polymerase coding region. J Virol. 2005;79:12650-7.

15. Apostol LN, Imagawa T, Suzuki A, Masago Y, Lupisan S, Olveda R, Saito M, Omura T, Oshitani H. Genetic diversity and molecular characterization of enteroviruses from sewage-polluted urban and rural rivers in the Philippines. Virus Genes. 2012;45:207-17.

16. Smura T, Blomqvist $\mathrm{S}$, Hovi T, Roivainen M. The complete genome sequences for a novel enterovirus type, enterovirus 96 , reflect multiple recombinations. Arch Virol. 2009:154:1157-61.

17. Xu A, Tao Z, Wang H, Zhang Y, Song L, Li Y, Liu G, Liu Y, Yang H, Fan Q, et al. The complete genome analysis of two enterovirus 96 strains isolated in China in 2005 and 2009. Virus Genes. 2011;42:323-30.

18. Nix WA, Khetsuriani N, Penaranda S, Maher K, Venczel L, Cselko Z, Freire MC, Cisterna D, Lema CL, Rosales $P$, et al. Diversity of picornaviruses in rural Bolivia. J Gen Virol. 2013:94:2017-28.

19. Duong V, Mey C, Eloit M, Zhu H, Danet L, Huang Z, Zou G, Tarantola A, Cheval J, Perot $P$, et al. Molecular epidemiology of human enterovirus 71 at the origin of an epidemic of fatal hand, foot and mouth disease cases in Cambodia. Emerg Microbes Infect. 2016;5:e104.

20. Xu W, Zhang Y. Isolation and characterization of vaccine-derived polioviruses, relevance for the global polio eradication initiative. Methods Mol Biol. 2016;1387:213-26.

21. Cui A, Xu C, Tan X, Zhang Y, Zhu Z, Mao N, Lu Y, Xu W. The development and application of the two real-time RT-PCR assays to detect the pathogen of HFMD. PLoS One. 2013;8:e61451.

22. Sun Q, Zhang Y, Zhu S, Tian H, Huang G, Cui H, Li X, Yan D, Zhu Z, Li J, et al. Transmission of human enterovirus 85 recombinants containing new unknown serotype HEV-B donor sequences in Xinjiang Uighur autonomous region, China. PLoS One. 2013;8:e55480.

23. Georgescu MM, Delpeyroux F, Tardy-Panit M, Balanant J, Combiescu M, Combiescu AA, Guillot S, Crainic R. High diversity of poliovirus strains isolated from the central nervous system from patients with vaccineassociated paralytic poliomyelitis. J Virol. 1994;68:8089-101.

24. Song Y, Zhang Y, Fan Q, Cui H, Yan D, Zhu S, Tang H, Sun Q, Wang D, Xu W. Phylogenetic characterizations of highly mutated EV-B106 recombinants showing extensive genetic exchanges with other EV-B in Xinjiang, China. Sci Rep. 2017;7:43080

25. Arita M, Shimizu H, Nagata N, Ami Y, Suzaki Y, Sata T, Iwasaki T, Miyamura T. Temperature-sensitive mutants of enterovirus 71 show attenuation in cynomolgus monkeys. J Gen Virol. 2005;86:1391-401.

26. Oberste MS, Maher K, Williams AJ, Dybdahl-Sissoko N, Brown BA, Gookin MS, Penaranda S, Mishrik N, Uddin M, Pallansch MA. Species-specific RT-PCR amplification of human enteroviruses: a tool for rapid species identification of uncharacterized enteroviruses. J Gen Virol. 2006:87:119-28.

27. Kumar S, Stecher G, Tamura K. MEGA7: molecular evolutionary genetics analysis version 7.0 for bigger datasets. Mol Biol Evol. 2016:33:1870-4.

28. Kalyaanamoorthy S, Minh BQ, Wong TKF, von Haeseler A, Jermiin LS. ModelFinder: fast model selection for accurate phylogenetic estimates. Nat Methods. 2017;14:587-9

29. Lole KS, Bollinger RC, Paranjape RS, Gadkari D, Kulkarni SS, Novak NG, Ingersoll R, Sheppard HW, Ray SC. Full-length human immunodeficiency virus type 1 genomes from subtype C-infected seroconverters in India, with evidence of intersubtype recombination. J Virol. 1999;73:152-60.

30. Belsham GJ, Sonenberg N. RNA-protein interactions in regulation of picornavirus RNA translation. Microbiol Rev. 1996;60:499-511.

31. Jackson RJ, Kaminski A. Internal initiation of translation in eukaryotes: the picornavirus paradigm and beyond. RNA. 1995:1:985-1000.

32. Lu J, Zheng H, Zhang Y, Guo X, Wu D, Li H, Liu L, Zeng H, Yi L, Fang L, et al. Whole genomic sequence and replication kinetics of a new enterovirus C96 isolated from Guangdong, China with a different cell tropism. PLoS One. 2014:9:e86877.

33. Zhang Y, Yan D, Zhu S, Nishimura Y, Ye X, Wang D, Jorba J, Zhu H, An H, Shimizu $H$, et al. An insight into recombination with enterovirus species $C$ and nucleotide G-480 reversion from the viewpoint of Neurovirulence of vaccine-derived polioviruses. Sci Rep. 2015;5:17291

34. Wu B, Qi X, Xu K, Ji H, Zhu Y, Tang F, Zhou M. Genetic characteristics of the coxsackievirus A24 variant causing outbreaks of acute hemorrhagic conjunctivitis in Jiangsu, China, 2010. PLoS One. 2014:9:e86883.

35. Smura T, Blomqvist S, Vuorinen T, Ivanova O, Samoilovich E, Al-Hello H, Savolainen-Kopra C, Hovi T, Roivainen M. The evolution of Vp1 gene in enterovirus C species sub-group that contains types CVA-21, CVA-24, EVC95, EV-C96 and EV-C99. PLoS One. 2014;9:e93737.

36. Bingjun T, Yoshida H, Yan W, Lin L, Tsuji T, Shimizu H, Miyamura T. Molecular typing and epidemiology of non-polio enteroviruses isolated from Yunnan Province, the People's Republic of China. J Med Virol. 2008;80:670-9.

37. Roberts LO, Seamons RA, Belsham GJ. Recognition of picornavirus internal ribosome entry sites within cells; influence of cellular and viral proteins. Rna. 1998:4:520-9.

38. Borman AM, Le Mercier P, Girard M, Kean KM. Comparison of picornaviral IRES-driven internal initiation of translation in cultured cells of different origins. Nucleic Acids Res. 1997;25:925-32.

39. Rohll JB, Percy N, Ley R, Evans DJ, Almond JW, Barclay WS. The 5'-untranslated regions of picornavirus RNAs contain independent functional domains essential for RNA replication and translation. J Virol. 1994;68:4384-91.

40. Muslin C, Joffret ML, Pelletier I, Blondel B, Delpeyroux F. Evolution and emergence of enteroviruses through intra- and inter-species recombination: plasticity and phenotypic impact of modular genetic exchanges in the $5^{\prime}$ untranslated region. PLoS Pathog. 2015;11:e1005266.

41. Kyriakopoulou Z, Pliaka V, Amoutzias GD, Markoulatos P. Recombination among human non-polio enteroviruses: implications for epidemiology and evolution. Virus Genes. 2015:50:177-88.

42. Norder H, Bjerregaard L, Magnius LO. Open reading frame sequence of an Asian enterovirus 73 strain reveals that the prototype from California is recombinant. J Gen Virol. 2002;83:1721-8.

43. Yang CF, De L, Yang SJ, Ruiz Gomez J, Cruz JR, Holloway BP, Pallansch MA, Kew OM. Genotype-specific in vitro amplification of sequences of the wild type 3 polioviruses from Mexico and Guatemala. Virus Res. 1992;24:277-96.

Ready to submit your research? Choose BMC and benefit from:

- fast, convenient online submission

- thorough peer review by experienced researchers in your field

- rapid publication on acceptance

- support for research data, including large and complex data types

- gold Open Access which fosters wider collaboration and increased citations

- maximum visibility for your research: over $100 \mathrm{M}$ website views per year

At $\mathrm{BMC}$, research is always in progress.

Learn more biomedcentral.com/submissions 